\title{
Demonstrative Pronouns as Anti-Logophoric Pronouns: An Experimental Investigation
}

\author{
Stefan Hinterwimmer \\ Germanistik - Linguistik \\ FB A - Geistes- und Kulturwissenschaften \\ Bergische Universität Wuppertal \\ Gaußstr. 20 \\ D-42119 Wuppertal
}

HINTERWIMMER@UNI-WUPPERTAL.DE

\section{Andreas Brocher}

A.BROCHER@GMX.DE

Umesh Patil

Institut für deutsche Sprache und Literatur I

Universität zu Köln

Albertus-Magnus-Platz

D-50923 Köln

\section{Editor: Jonathan Ginzburg}

Submitted 05/2019; Accepted 10/2020; Published online 10/2020

\begin{abstract}
In this paper we report the results of two experimental studies in which we tested the claim of Hinterwimmer and Bosch (2017) that German demonstrative pronouns are anti-logophoric pronouns: They avoid discourse referents as antecedents that function as perspectival centers. In both experiments we tested the interpretative options of demonstrative pronouns in text segments which were either perspectivally neutral or in which the narrator's or a topical protagonist's perspective was foregrounded. Taken together, the experimental results are most compatible with a slightly modified version of the analysis argued for in Hinterwimmer and Bosch (2017) according to which topical discourse referents in neutral narration automatically become perspectival centers.
\end{abstract}

\section{Introduction}

In this paper we report the results of two experimental studies in which we tested the claim of Hinterwimmer and Bosch (2017) that German demonstrative pronouns of the der (he)/die (she)/das (it) series (henceforth: DPros) avoid discourse referents as antecedents that function as perspectival centers. The term perspectival center is defined as follows: A discourse referent $\alpha$ is the perspectival center with respect to a proposition $p$ if $p$ is the content of a mental state of the semantic value of $\alpha$ (i.e. $g(\alpha)$, where $g$ is the assignment function). The clearest instances of perspectival centers are the subjects of propositional attitude verbs such as think or believe: The proposition denoted by the complement clause of such a verb is the content of a mental state of the subject. Consequently, the subject is the perspectival center with respect to that proposition. Adopting a possible worlds semantics along the lines of Hintikka (1969), the denotation of a sentence such as (1a) can thus be paraphrased as in (1b). 
(1) a. Stanley believes that Trump will win the election in 2020.

b. In all worlds that are compatible with Stanley's beliefs at the utterance time, Trump wins the election in 2020 .

A second case where discourse referents clearly function as perspectival centers is Free Indirect Discourse (henceforth: FID). FID is a form of speech or thought representation that is often found in fictional narrative texts. Like in indirect discourse (an instance of which is given in (1a)), in FID a sentence is interpreted as the content of a thought or utterance of some discourse referent. In contrast to indirect (and direct) discourse, however, such an interpretation is not enforced by the presence of a propositional attitude verb under which the respective sentence is embedded. Rather, sentences in FID are autonomous, unembedded sentences such as (2a) whose interpretation as a thought or utterance has to be inferred by the reader. This inference is either triggered by the content exclusively or by the content in combination with clues such as the presence of deictic expressions that can only be interpreted sensibly with respect to the context of some prominent discourse referent. In the case of (2a), for instance, the deictic temporal adverb tomorrow can only be interpreted with respect to Mary's context, as referring to the day following the day on which she looked at her tablet with sheer panic. If tomorrow was interpreted with respect to the narrator's context, the resulting interpretation would be contradictory since an event or state cannot at the same time be located in the past and in the future.

Mary looked at her tablet in sheer panic.

a. Tomorrow she had to submit her paper, and she had not even written two pages.

If (2a) is interpreted as a thought that Mary has while looking at her tablet in sheer panic, however, and if tomorrow is interpreted with respect to Mary's context, while the past tense is interpreted with respect to the narrator's context, there is no such contradiction (see Doron, 1991; Schlenker, 2004; Sharvit, 2008; Eckardt, 2014 and Maier, 2015 for different analyses of FID in a formal semantics framework and Rauh, 1978 and Banfield, 1982 for early analyses of FID in a generative framework). Mary is thus the perspectival center with respect to (2a).

Since the seminal work of Clements (1975) on the pronoun system of the West African language Ewe (see Pearson, 2015 for a recent analysis), it is well known that many languages of the world have special pronouns that can only be used to pick up antecedents that are perspectival centers (see Sells, 1987 for an overview): The clause containing a pronoun of this kind has to be interpreted as the content of a mental state of the antecedent. Such pronouns are called logophoric pronouns. Relatedly, many languages such as Icelandic, Tamil and Japanese allow long-distance uses of reflexive pronouns in logophoric environments, i.e. in cases where the antecedent is a perspectival center (see Sundaresan, 2012; Nishigauchi, 2014 and Charnavel, 2019 for recent discussion). At the same time, Dubinsky and Hamilton (1998) and Patel-Grosz (2014) have argued that epithets such as the idiot are anti-logophoric pronouns since they cannot be interpreted as picking up discourse referents functioning as perspectival centers - more precisely, when they occur in the complement clause of a propositional attitude verb or a sentence in FID, they have to be interpreted as referring to an individual that is distinct from the subject of the propositional attitude verb in the former case and the implicit thinker or speaker in the latter. Relatedly, Charnavel and Mateu (2015) and Yashima (2015) have argued for the existence of anti-logophoric pronouns in French, Spanish and Japanese.

Hinterwimmer and Bosch (2017) observe that German DPros, which in previous literature have been assumed to avoid subjects (Bosch et al. 2007), topics (Bosch and Umbach 2006; Hinterwimmer 2015) or (proto-)agents as antecedents, can sometimes pick up subjects, topics and (proto-)agents. This is possible whenever the speaker or narrator is clearly present as perspectival center, i.e. whenever the sentence containing the DPro is interpreted as the content of a thought expressing the narrator's stance. If the discourse referent functioning as subject, topic and/or proto-agent is the perspectival center, in contrast, such an interpretation is not available. Hinterwimmer and Bosch (2017) take this contrast to show that DPros are antilogophoric pronouns avoiding perspectival centers as antecedents. More tentatively, they 
propose that the entire distribution of DPros can be derived from anti-logophoricity: First, they assume that (what seems to be) avoidance of subjects and (proto-)agents are actually epiphenomena of topic avoidance. Second, they assume that in neutral narration, where no speaker or narrator is present as perspectival center, topics are perspectival centers by default and are therefore avoided by DPros as antecedents. Although this aspect is not worked out in any detail, the basic idea is that sentences in neutral narration are interpreted as the contents of perceptions of the topical referent (see Brinton, 1980; Palmer, 2004; Farner, 2014 and van Krieken, 2018 for relevant discussion).

We tested the predictions of Hinterwimmer and Bosch's (2017) account with two experimental studies in which we compared the interpretative options of DPros in text segments which were either perspectivally neutral or in which the narrator's or a topical protagonist's perspective was foregrounded. Taken together, the experimental results are most compatible with a slightly modified version of the analysis argued for in Hinterwimmer and Bosch (2017) according to which topical referents automatically become perspectival centers in neutral narration.

The paper is structured as follows, In Section 2 we first give a brief overview over previous work on DPros in German, before we present the analysis of Hinterwimmer and Bosch (2017). In Section 3 the two experimental studies are presented and discussed. Section 4 is the conclusion.

\section{Background}

\subsection{Previous work on DPros in German}

Like many languages, such as Finnish, Dutch, and Catalan (see, e.g. Kaiser and Trueswell, 2008; Kaiser, 2010, 2011a, 2011b, 2013; Mayol and Clark, 2010), German has two pronoun series: The first one consists of the personal pronouns (henceforth: PPros) er/sie/es ('he'/'she'/'it') together with their various forms. The second series consists of the so-called demonstrative pronouns (DPros) der/die/das, which are morphologically identical to the definite article. There is a further series of demonstrative pronouns in German, which is, however, largely confined to somewhat formal registers (see Patil, Bosch and Hinterwimmer, 2020), and will not be discussed in this paper: the dieser/diese/dieses-series.

Generally, in languages with two or more pronoun series, weight or length, and therefore the associated markedness, varies across them (see the references above). This clearly applies to German as well, with er being shorter than $\operatorname{der}$ (see Patel-Grosz and Grosz, 2017). As pointed out by Kaiser and Trueswell (2008), Kaiser (2010; 2011a; 2011b; 2013) and Mayol and Clark (2010), marked pronouns display a more limited distribution than unmarked pronouns. There is also a general consensus in the literature that German DPros avoid maximally prominent antecedents. Assumptions differ, however, regarding the question of which properties are decisive for maximal prominence. On the basis of contrasts like the one between the DPro- and the PPro-variant of the second sentence in (3), Bosch et al. (2007) argue for the following claim: DPs functioning as the subject of immediately preceding sentences are maximally prominent and therefore avoided by DPros. Bosch and Umbach (2006), however, observe that in some cases DPros actually have a strong preference for the subject of the preceding sentence: The DPro in the third sentence in (4) can only be interpreted as referring to the subject of the preceding sentence, Peter, not the indirect object, Karl.

(3) Mark $k_{i}$ hat gestern mit $\operatorname{Noah}_{j}$ gesprochen. $\operatorname{Der}_{j} *_{i} / \operatorname{Er}_{i j}$ hat sich einen neuen Ferrari gekauft. Mark $_{i}$ talked to Noah $_{j}$ yesterday. He(DPro $)_{j} *_{i} / H_{i, j}$ bought himself a new Ferrari.

(4) Woher Karl $\mathrm{K}_{\mathrm{i}}$ das weiß? Peter $\mathrm{j}_{\mathrm{j}}$ hat es $\mathrm{ihm} \mathrm{i}_{\mathrm{i}}$ gesagt. $\operatorname{Der}_{\mathrm{j} / *_{\mathrm{i}}} / \mathrm{Er}_{\mathrm{i}, \mathrm{j}}$ war gerade hier. How does Karl $k_{i}$ know? Peter told $_{\text {it to }}$ him $_{i}$. He(DPro $)_{j / *_{i}} / \mathrm{He}_{i, j}$ has just been here. 
According to Bosch and Umbach (2006), this is due to Karl being the topic of the entire discourse segment: Karl is introduced in the opening sentence and picked up by a PPro in the second sentence. Additionally, the first sentence asks and the second sentence answers a question about Karl. The subject of the second sentence, in contrast, is contained in the focal part of the sentence. That part provides new information that answers the question asked by the first sentence. Based on these and similar observations, Bosch and Umbach (2006) propose that DPros avoid discourse topics because they are the most prominent antecedents. What seems to be subject avoidance in cases like (3) is, in their view, an epiphenomenon of topic avoidance, since there is a (crosslinguistically quite stable) tendency for discourse topics to be realized as subjects. When the two notions diverge, however, as in (4), DPros avoid topics, not subjects.

In Hinterwimmer (2015), this proposal is taken up and further generalized along the following lines (see Hinterwimmer and Brocher, 2018 for experimental evidence): In cases of co-reference such as in (3) and (4), where the antecedent and the pronoun appear in separate sentences and where there is no structural relation between antecedent and pronoun, (maximal) prominence is defined in terms of topicality. In cases like (5a-d), in contrast, where binding is at play and where there is a structural relation between antecedent and pronoun, namely ccommand, maximal prominence is defined in terms of subjecthood. Consequently, not only the PPro in (5a), but also the DPro in (5b) receives a bound interpretation, as the potential binder is an indirect object. In (5d), in contrast, where the only potential binder is the subject, a bound interpretation is unavailable for the DPro, unlike for the PPro in (5c). Note that since seine is the possessive version of the PPro er and dessen the possessive version of the DPro der, there is no reason to expect that they behave differently from their respective nominative versions with respect to the constraint under discussion.

a-b. Frau Bauer bringt [jedem Buchhalter $]_{i}$ seine $_{i} /$ dessen $_{i}$ neue Daten, die schon lange fällig waren.

Mrs. Bauer brings [every accountant $]_{i}$ his $/$ his $(\text { DPro })_{i}$ new data, which have been overdue for a while.

c-d. [Jeder Buchhalter $]_{\mathrm{i}}$ bringt Frau Bauer seine ${ }_{\mathrm{i}} /$ dessen $_{*_{\mathrm{i}}}$ neue(n) Daten, die schon lange fällig waren.

[Every accountant $]_{i}$ brings Mrs. Bauer his ${ }_{i} /$ his $(\text { DPro })_{*}$ new data, which have been overdue for a while.

Schumacher et al. (2016) and Schumacher et al. (2017) have added agentivity to the various features that can affect prominence. Based on experimental evidence, they claim that in sentences with dative experiencer verbs, such as the opening sentence in (6), the referent of the dative object is more prominent than the referent of the subject because it has an additional agentivity feature, namely sentience. Consequently, a DPro contained in the subsequent sentence can only be interpreted as the subject DP. Since the argument with the highest number of agentivity features is typically realized as subject (see Dowty, 1991; Primus, 1999; 2006), subject-avoidance might be a side effect of more general differences in agentivity.

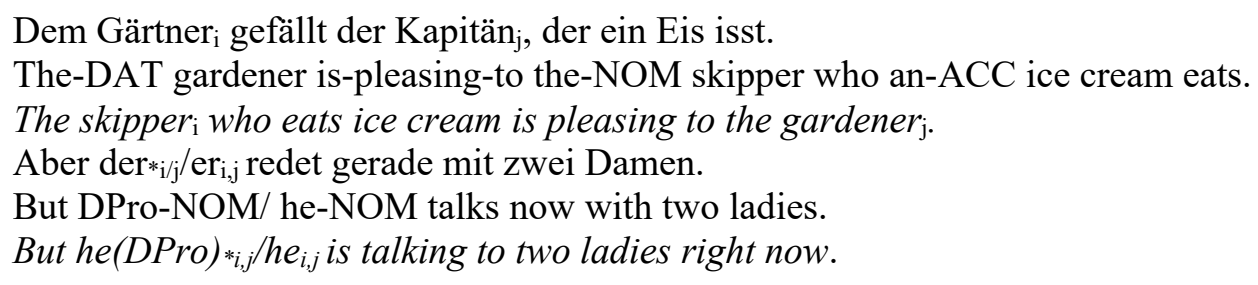

Now, in contrast to cases where the dative object is fronted, there is no clear preference for either of the two potential antecedents in cases like in (7). Here it is the subject that is fronted. From this, Schumacher et al. (2016) and Schumacher et al. (2017) conclude that prominence in terms of topicality plays a role as well. The idea is that fronted DPs are likely to be interpreted as topics: In cases like in (6), prominence in terms of topicality then coincides with prominence in terms of agentivity, resulting in a clear interpretation preference for the less prominent 
referent. In (7), in contrast, the two notions go in opposite directions. Consequently, there is no clear preference anymore.
Der Kapitän $n_{i}$ gefällt dem Gärtner ${ }_{j}$, der ein Eis isst.
The-NOM skipper is-pleasing-to the-DAT gardener who an-ACC ice cream eats.
The skipper $r_{\mathrm{i}}$ is pleasing to the gardener $r_{\mathrm{j}}$, who eats ice cream.
Aber $\operatorname{der}_{\mathrm{ij}} / \mathrm{er}_{\mathrm{i}, \mathrm{j}}$ redet gerade mit zwei Damen.
But DPro-NOM/ he-NOM talks now with two ladies.
But he(DPro $)_{i, j} /$ he $_{i, j}$ is talking to two ladies right now.

\subsection{DPros as anti-logophoric pronouns}

As already said in Section 1, Hinterwimmer and Bosch (2017) claim that the distribution of DPros can largely be derived from anti-logophoricity rather than from subject-, topic-, or agentavoidance: DPros may not pick up discourse referents functioning as perspectival centers with respect to the proposition denoted by the clause that contains the respective DPro. Recall that a discourse referent $\alpha$ is the perspectival center with respect to a proposition $p$ if $p$ is the content of a mental state of the semantic value of $\alpha$. The crucial observation motivating the account of Hinterwimmer and Bosch (2017) is that in some cases DPros can pick up discourse referents that are the subjects (pace Bosch et al., 2007), topics (pace Bosch and Umbach, 2006; Hinterwimmer, 2015) and agents (pace Schumacher et al., 2016; 2017) of the preceding sentence, while in other cases this is completely impossible. Compare the continuations of (8) in (8a) and (8b), respectively: (The proper name referring to) Peter is the subject of the main clause in (8) and the agent of the eventuality introduced by the main clause verb sighed. Additionally, since there are no contextual factors overwriting the tendency for topics to be realized as subjects, he is the topic by default as well. Nevertheless, the DPro in (8a) can easily be understood as picking up Peter, while this is completely impossible for the DPro in (8b). Since the preceding sentence is the same in both cases, this contrast cannot be due to any difference regarding subjecthood, (proto-) agentivity or topicality, and therefore is completely unexpected on all accounts discussed in Section 2.1: Peter should be unavailable as an antecedent for the DPro not only in (8b), but in (8a) as well.

$$
\begin{aligned}
& \text { Peter }{ }_{i} \text { seufzte, als er die Tür öffnete und sah, dass die Wohnung mal wieder in einem } \\
& \text { fürchterlichen Zustand war. } \\
& \text { Peter } r_{\mathrm{i}} \text { sighed when he opened the door and saw that the flat was in a terrible state } \\
& \text { again. } \\
& \text { a. Der } \mathrm{kann} \text { sich einfach nicht gegen seinen Mitbewohner durchsetzen. } \\
& \text { He(DPro } \left.{ }_{i}\right) \text { is simply unable to stand his ground against his flatmate. } \\
& \text { b. Verdammt, der } *_{i} / \mathrm{er}_{\mathrm{i}} \text { hatte doch gestern erst aufgeräumt. } \\
& \text { Damn, he }\left(D P r o *_{i}\right) / h e_{i} \text { had only tidied up yesterday, after all. }
\end{aligned}
$$

The contrast between (8a) and (8b) can be accounted for if one assumes DPros to be antilogophoric pronouns, however: The continuation in (8a) is most plausibly understood as expressing a general comment about Peter by the narrator. This is indicated by the content in combination with the switch from past to present tense, which breaks narrative continuity. The narrator is thus the perspectival center with respect to the proposition denoted by (8a), since that proposition is the content of a mental state (namely a thought) of the narrator on the most plausible interpretation. Anti-logophoricity is therefore not violated if the DPro in (8a) is interpreted as picking up Peter, since Peter is not the perspectival center with respect to the proposition denoted by $(8 \mathrm{a})$.

The continuation in (8b), in contrast, is most plausibly understood as expressing a thought of Peter in FID. This is indicated by the content in combination with the presence of the deictic temporal adverb gestern ('yesterday'), the modal particle doch and the evaluative expression verdammt ('damn'). The deictic temporal adverb gestern is more plausibly interpreted with respect to Peter's than with respect to the narrator's context, i.e. as referring to the day preceding 
the day on which Peter came home in the evening. Likewise, the modal particle doch, which indicates that the proposition denoted by the clause containing the modal particle violates a previously held assumption, is more plausibly interpreted as violating Peter's expectations than the narrator's. Finally, verdammt most likely expresses Peter's frustration, not the narrator's.

As already said in Section 1, FID is a special form of speech or thought representation in which all context-sensitive expressions with the exception of pronouns and tenses are interpreted with respect to some prominent protagonist's context. The author of that context is the respective protagonist, the temporal parameter is provided by the reference time of the ongoing story and the spatial parameter is the location of the protagonist at the reference time. Concerning pronouns and tenses, they are interpreted with respect to the narrator's context (see Schlenker, 2004; Sharvit, 2008 and Eckardt, 2014 for different versions of the double context analysis and Maier, 2015 for an analysis according to which FID is a special form of mixed quotation in which pronouns and tenses are unquoted). On its most plausible interpretation as FID, Peter is therefore the perspectival center with respect to the proposition denoted by $(8 \mathrm{~b})$ since that proposition is the content of a mental state (namely a thought) of Peter. Consequently, anti-logophoricity is violated if the DPro in (8b) is interpreted as picking up Peter - at least if $(8 b)$ is interpreted as FID. If ( $8 b)$ is interpreted as expressing a thought of the narrator (a rather implausible, but not completely excluded option), in contrast, the DPro can of course be interpreted as picking up Peter.

From contrasts like the one between $(8 \mathrm{a})$ and $(8 \mathrm{~b})$, which cannot be interpreted in terms of subject-, topic-, or (proto-)agent-avoidance, but in terms of anti-logophoricity, Hinterwimmer and Bosch (2017) conclude that DPros are anti-logophoric pronouns. Additionally, they note that the contrast between the interpretative options of DPros and PPros in sentences like (9ab), which has already been observed by Wiltschko (1998), cannot only be accounted for in terms of subject-avoidance, but also in terms of anti-logophoricity: DPros cannot be interpreted as co-referential with or bound by the subjects of propositional attitude verbs since the individuals referred to or quantified over by the respective subject DP are perspectival centers with respect to the proposition denoted by the complement clause of the propositional attitude $\operatorname{verb}^{1}$.

\footnotetext{
${ }^{1}$ Concerning the complement clauses of propositional attitude verbs, the situation is actually more complicated. Hinterwimmer \& Bosch (2017) observe that in sentences with double embedding such as (i-ii) DPros can be interpreted as co-referential with or bound by the subject of the embedded propositional attitude verb, but not by the subject of the matrix propositional attitude verb.

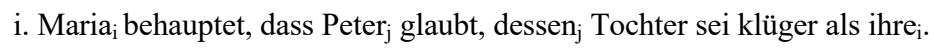

Maria $_{i}$ claims that Peter $\mathrm{j}_{\mathrm{j}}$ believes that his $\left\{\right.$ DPro $\left._{j}\right\}$ daughter is smarter than hers ${ }_{i}$.

ii. Maria $\mathrm{i}_{\mathrm{i}}$ behauptet, dass Peter $_{\mathrm{j}}$ glaubt, deren ${ }_{*} /$ ihre $_{\mathrm{i}}$ Tochter sei klüger als seine $\mathrm{j}_{\mathrm{j}}$.

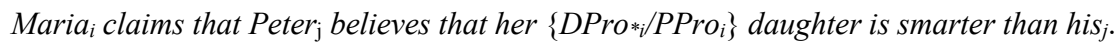

Hinterwimmer \& Bosch (2017) draw the following conclusion from this observation: DPros avoid the most prominent perspectival center. In the cases discussed so far, there is just one perspectival center, which is thus automatically the most prominent one. In cases like (i) and (ii), in contrast, the subject of the matrix propositional verb is the more prominent perspectival center than the subject of the embedded one, for the following reason: The referent of the matrix clause subject is the perspectival center with respect to the proposition denoted by the complement clause of the matrix propositional attitude verb. That proposition in turn contains the referent of the embedded subject as well as the proposition with respect to which that referent is the perspectival center. The referent of the matrix clause subject is therefore the superordinate perspectival center, and the referent of the embedded subject is the subordinate perspectival center, and Hinterwimmer \& Bosch (2017) assume that superordination corresponds to higher prominence. We have tested the claims of Hinterwimmer \& Bosch (2017) concerning the interpretative options of DPros in sentences like (i) and (ii) in a reading time and an acceptability rating study. The predictions were confirmed: Sentences like (i), in which the DPro in the most deeply embedded clause could only be interpreted as co-referential with the embedded, but not the matrix clause subject were read faster and rated better than sentences where it was the other way round. We omitted discussion of these experiments from the article, however, since their results do not directly provide arguments for anti-logophoricity, as pointed out to us by two anonymous reviewers: They could just as well be explained by topic avoidance, since the matrix clause subjects can plausibly be regarded as topics by default.
} 
a. Maria $a_{i}$ glaubt, dass die $*_{i} /$ sie $_{i}$ ein Genie ist.

Maria believes that she $\left\{\right.$ DPro $*_{i} /$ PPro $\left._{i}\right\}$ is a genius.

b. [Jeder Mann] $]_{i}$ glaubt, dass der $_{*} /$ er $_{i}$ ein Genie ist.

[Every man $]_{i}$ believes that he $\left\{\right.$ DPro $*_{i} /$ PPro $\left._{i}\right\}$ is a genius.

Concerning the question of why in sentences like in (3) and (4), the DPro can only refer to the non-topical referent and why it cannot be interpreted as bound by the subject quantifier in cases like (5d), Hinterwimmer and Bosch (2017) argue as follows: When there is no indication of the presence of a perspectival center (i.e. in cases of neutral narration), the respective topic or the individuals quantified over by the subject quantifier are interpreted as perspectival centers by default. The authors do not discuss cases like (6) and (7), but such cases can be accounted for under the assumption that DPros avoid (the most prominent) perspectival centers: Because of sentience, it is quite natural to interpret the experiencer argument of a verb as perspectival center with respect to the proposition denoted by the clause containing that verb. Interpreting the stimulus argument as perspectival center is rather unnatural, in contrast, at least when it occurs in (canonical) clause-internal position. If the stimulus argument is fronted, however, this might be taken as indication that it is the aboutness topic. Consequently, in the absence of a speaker or narrator functioning as perspectival center, it becomes a potential perspectival center as well. This results in unclear interpretation preferences.

The argumentation in Hinterwimmer and Bosch (2017) is largely based on the two authors' introspectively gained native speaker intuitions, and the contrasts that are reported are rather subtle. Although informally gained introspective judgments are valuable for formulating linguistic hypotheses, they are arguably insufficient for theory building as such (see e.g. Gibson and Fedorenko, 2013). To address this limitation, we conducted two offline rating experiments to gain more solid empirical evidence for the claims made in Hinterwimmer and Bosch (2017).

We tested the following hypothesis: DPros can pick discourse referents that function as subject, agent, and topic of the preceding sentences as long as there exists a perspectival center that is different from these discourse referents. In other words, DPros avoid perspectival centers. If the topical discourse referents are at the same time perspectival centers with respect to the proposition denoted by the sentence containing the DPro, in contrast, they cannot be picked up by that DPro. In order to test this hypothesis, we compared the following two types of sentences: sentences in FID, where the discourse referent functioning as topic, agent and subject of the preceding sentence is at the same time the perspectival center, and sentences where clearly the narrator is the perspectival center.

We also tested whether there is only a weak tendency to interpret topics as perspectival centers, or whether topics are automatically interpreted as perspectival centers whenever there is no indication of the narrator functioning as perspectival center. To that end, we compared sentences in FID and sentences where the narrator is the perspectival center with neutrally narrated sentences. If there is only a weak tendency to interpret topics as perspectival centers, it should be easier for DPros contained in neutrally narrated sentences to pick up topical discourse referents than for DPros contained in FID-sentences: In the latter case, antilogophoricity is necessarily violated, while in the former case violating it can be avoided by interpreting the respective sentence as reporting the abstract narrator's rather than the (semantic value of the) topical discourse referent's perspective. If topical discourse referents automatically become perspectival centers whenever there is no indication of a speaker or narrator functioning as perspectival center, in contrast, the interpretative options of DPros should be the same in neutrally narrated sentences and in sentences in FID.

\section{The Experimental Studies}

\subsection{Overview}

In the two experiments to be discussed in this section, we used offline rating tasks to test whether a topical discourse referent can be referred to with a DPro in sentences that express evaluation of the narrator as opposed to sentences that express a thought of the topical discourse referent in FID (cf. Hinterwimmer and Bosch, 2017). In the two experiments, we also tested 
whether there is only a weak tendency to interpret topical discourse referents as perspectival centers or whether they are automatically interpreted as perspectival centers whenever there is no evidence of a speaker or narrator functioning as perspectival center.

(10) Als Fabian zur Arbeit ging, fand er 100 Euro auf dem Gehweg.

When Fabian went to work, he found 100 Euros on the sidewalk.

[Narrator-judgement]

a-b. Er/Der hat einfach immer so ein unverschämtes Glück.

$\mathrm{He} / \mathrm{He}_{\mathrm{DPro}}$ simply always is so incredibly lucky.

[FID]

c-d. Toll, er/der würde heute Abend davon schick essen gehen.

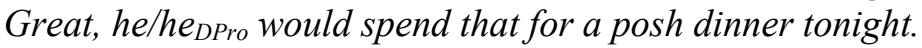

[Neutral]

e-f. Er/Der kaufte sich von dem Geld ein Paar neue Schuhe.

$H e / H e_{D P r o}$ bought a pair of new shoes with the money.

In (10), the individual introduced in the opening sentence ('Fabian') is established as the discourse topic of the text segment, and the DPs referring to that individual in the adjunct and the matrix clause of the first sentence are both the subject and the agent with respect to those clauses. Therefore, on the assumption that DPros avoid topics, subjects, and/or agents, we predict DPros in all three variations to be judged equally bad (and worse than the corresponding PPros).

On the other hand, if avoidance of the perspectival center is the relevant constraint, the DPro in Narrator-judgement conditions should be rated as more acceptable than the DPro in the other two conditions. This is expected because in Narrator-judgement conditions, the discourse topic is not the perspectival center anymore, but the abstract narrator is. Between the other two conditions, the DPro in the FID condition should be rated as less acceptable than the DPro in the Neutral condition if there is only a weak tendency to interpret topics as perspectival centers since it should then also be possible to interpret sentences in that condition as reported from the abstract narrator's perspective, i.e. with the narrator functioning as perspectival center. If topics automatically become perspectival centers whenever there is no indication of the speaker or narrator functioning as perspectival center, in contrast, there should be no contrast in ratings of DPros between the two conditions. Finally, for the PPro, we expected no variation in ratings across the three conditions because it is an unmarked pronoun.

\subsection{Experiment 1}

\section{Method}

\section{Participants}

Eighty-five native speakers of German were recruited through Prolific (https://prolific.ac/) for monetary compensation (£2.04).

\section{Materials}

We constructed 36 experimental items each consisting of two sentences, as in (10), interspersed with 36 fillers. The first sentence, which was the same across all conditions, established an individual referred to by a proper name as topic. The second sentence had three possible continuations, each of which occurred with a PPro and a DPro. This resulted in a total of six conditions. In Narrator-judgement conditions (conditions $a$ and $b$ ), the second sentence clearly expressed an evaluation of the topical referent by the narrator, as indicated by the content in combination with a switch from past tense to present tense (as in (8a) from section 2.1 above). In condition $a$, the topical referent was referred to by a PPro, and in condition $b$ it was referred to by a DPro.

In FID conditions (conditions $c$ and $d$, where in condition $c$, the topical referent is referred to by a PPro, and in condition $d$ by a DPro), the second sentence is most plausibly interpreted 
as a thought of the topical referent rendered as FID. We always used two indicators for FID: An interjection such as toll ('great') and a deictic element such as heute ('today') that in combination with past tense are typically interpreted with respect to the topical referent's (fictional) context, not with respect to the narrator's context. Note, however, that we cannot completely exclude the option of interpreting the final sentence as expressing the narrator's evaluation, i.e. as claiming in the case of $(10 \mathrm{c}-\mathrm{d})$, for example, that the narrator finds it great that the topic of the discourse (Fabian) will, according to her/his expectations, spend the money for a posh dinner on the evening of the day on which the narrator tells her/his story. The participants' task is thus actually twofold in the two conditions: On the one hand, they have to recognize the final sentence in both conditions as FID, and on the other hand they have to resolve the respective pronoun. The two tasks are not completely independent from one another since the DPro is only excluded from picking up the topical referent when the final sentence is interpreted as FID, but not when it is interpreted as expressing the narrator's perspective. ${ }^{2}$ This is a potential shortcoming of our experimental design that we will come back to in the final discussion. Finally, the Neutral conditions (conditions $e$ and $f$ ), are neutral narrative continuations, where in $e$ the topical referent is referred to by a PPro, and in $f$ by a DPro. On the assumption that there is only a weak preference for interpreting topics as perspectival centers in the absence of any indication of the speaker or narrator functioning as perspectival center, the participants' task is twofold on those two conditions, too: In addition to resolving the pronoun, they have to decide whether they assume the respective final sentence to express the narrator's or the topical referent's perspective. Again, the two tasks are not independent from one another since the DPro is only prohibited from picking up the topical referent if the latter is assumed to be the perspectival center. ${ }^{3}$ On the assumption that topical referents automatically become perspectival centers in the absence of any indication of a speaker or narrator functioning as perspectival center, in contrast, the participants' sole task consist in resolving the respective pronouns, where DPros are excluded from being resolved to the topical referent.

\section{Procedure}

The experiment involved a 'yes'/'no' judgment task. Participants were instructed that the texts were beginnings of short stories produced by advanced German learners, where each example text was produced by a different learner. Participants' task was to judge whether the student had reached native-like proficiency in German (by responding 'yes, they have' or 'no, they have not'). The reason why we asked participants to judge language proficiency instead of acceptability was that judging acceptability could be influenced by factors such as prescriptive knowledge of the grammar and metalinguistic reasoning such as the plausibility of the text (Schütze, 2016: 81-88). Due to this potential vagueness of the acceptability rating task we wanted to explore an alternative task that native speakers are used to performing in everyday life - judging fluency of a non-native speaker. ${ }^{4}$ For methodological comparison, we also carried out an experiment using the same items with conventional acceptability rating task (see Expt. 2).

\section{Data analysis}

All data processing and analyses were carried out in R (R Core Team, 2018). We fitted generalized linear mixed models with logit link function (Jaeger, 2008), where the dependent variable was the binary response (native or non-native) and the fixed effects were: 1 . sentence type (three levels: Narrator-judgement, FID, and Neutral), 2. pronoun type (two levels: PPro and DPro), and 3. their interaction. Since we intended to compare the effect of Narratorjudgement and FID conditions with the Neutral conditions we fitted a model with treatment

\footnotetext{
${ }^{2}$ We are grateful to an anonymous reviewer for pointing this out to us.

${ }^{3} \mathrm{We}$ are grateful to an anonymous reviewer for pointing this out to us.

${ }^{4}$ Given the fact that among 175-220 million German speakers worldwide, 85-125 million speakers speak German non-natively (Geographical distribution of German speakers, n.d.), it is evident that German native speakers are commonly exposed to non-native German usage.
} 
contrast with Neutral condition as the reference level. We inserted random intercepts for participants and items. Models with maximal random effects structure did not converge.

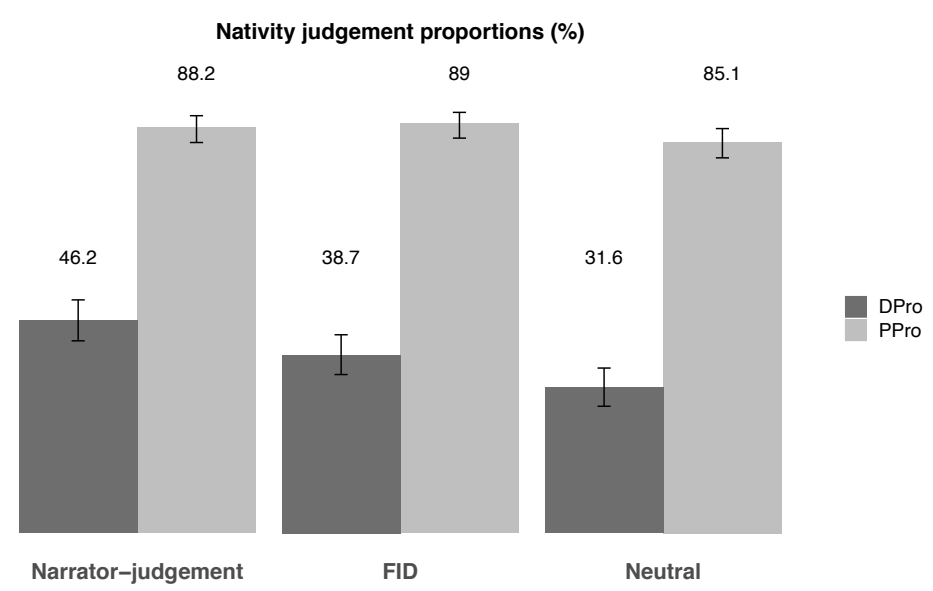

Figure 1. Proportions of DPro/PPro trials rated as native in Experiment 1.

\begin{tabular}{l|rrcl} 
Fixed effects & Estimate & Std.Error & $\mathrm{p}$ & \\
Intercept & -0.834 & 0.154 & $<10^{-7}$ & $*$ \\
FID & 0.338 & 0.145 & 0.0197 & $*$ \\
Narrator-judgement & 0.647 & 0.144 & $<10^{-5}$ & $*$ \\
Pronoun type & 2.872 & 0.173 & $<10^{-15}$ & $*$ \\
FID : Pronoun type & -0.015 & 0.241 & 0.949 & \\
Narrator-judgement : Pronoun type & -0.479 & 0.237 & 0.0427 & $*$
\end{tabular}

Table 1: Linear model estimates, standard errors and p-values for the data from Experiment 1. Neutral is the reference level. Estimates for FID and Narrator-judgement show the effect of these two sentence types with respect to sentences in Neutral type; the estimate for Pronoun type shows the effect of PPro with respect to DPro; and estimates for FID : Pronoun type and Narrator-judgement : Pronoun type show the interaction between FID sentences and the type of the pronoun, and Narrator-judgement sentences and the type of the pronoun.

\section{Results}

The mean proportions of responses are plotted in Figure 1 and the fixed effects from the linear models are provided in Table 1. In the first model (see Table 1), where Neutral was the reference level, there were significant main effects of sentence type and pronoun type: Narrator-judgement and FID sentences were judged as more native-like than Neutral sentences, and PPros were judged as more native-like than DPros. The interaction of Narratorjudgement and Neutral sentence types with pronoun type was also significant. However, the second interaction of FID and Neutral sentence types with pronoun type did not reach significance.

Pairwise comparisons for the effects of DPro between Narrator-judgement and Neutral, on the one hand, and Narrator-judgement and FID on the other revealed that DPros were judged as significantly more native-like in the Narrator-judgement condition in both cases. We did not carry out a pairwise comparison between the DPro in FID and Neutral conditions because, although there was a numerical difference in the ratings for the DPro between these two conditions, their interaction did not turn out to be significant in the earlier model.

\section{Discussion}

We defer the discussion of Experiment 1 to the discussion of Experiment 2, as both experiments asked the same question, using the same materials but different experimental paradigms. 


\subsection{Experiment 2}

We carried out Experiment 2 to replicate the effects from Experiment 1 using a slightly different methodology. Moreover, we aimed at checking whether the DPro was in fact rated as more native-like in the FID condition than in the Neutral condition. Although this effect did not turn out to be statistically reliable in the previous experiment, there was a numerical trend and this trend was unexpected under both variants of the anti-logophoricity account under investigation (i.e. both on the assumption that there is just a weak tendency to interpret topical referents in the absence of any indication of a speaker or narrator functioning as perspectival center and on the assumption that topical referents automatically become perspectival centers in such cases). To that end, we employed a dual-task that combined a forced-choice with an acceptability rating task, such that we elicited two responses from each participant. Because, among the conventional offline tasks used for eliciting linguistic judgements, the forced-choice task provides maximum power (Schütze and Sprouse, 2014), we reasoned that this task should reveal differences between the FID and the Neutral condition for DPros, if there are any. Also, the secondary task allowed us to validate the results from the nativity judgement task in Experiment 1 with a more conventional acceptability task.

\section{Method}

\section{Participants}

Forty-six native speakers of German were recruited from the University of Cologne for course credits.

\section{Materials}

We used the same 36 experimental items as in Experiment 1. These items were again interspersed with 36 fillers.

\section{Procedure}

The experiment was an offline dual task - a forced-choice task followed by an acceptability rating task. In each trial, participants were shown a sentence, just like the first sentence in (10), followed by two continuations, like the second sentences in (10). One continuation contained a PPro, the other a DPro. Participants were asked to choose the continuations that they found more acceptable and then rate the continuation they did not select for naturalness on a scale from 1 (for "completely acceptable") through 7 (for "completely unacceptable"). In case participants found both continuations equally plausible, they were asked to only engage in the acceptability task.

\section{Data analysis}

All data pre-processing and analyses were carried out in R (R Core Team, 2018). We fitted Generalized Linear Mixed Models with logit link function (Jaeger, 2008) for the first response (forced-choice). The dependent variable was the binary judgment PPro or DPro and the fixed effect was sentence type, with the three levels Narrator-judgement, FID, and Neutral. Since we wanted to compare the effect of Narrator-judgement and FID conditions with the Neutral conditions, as well as potential differences between the Narrator-judgement and FID, we fit two separate models with treatment contrasts: In the first model, Neutral was used as reference level and in the second, FID. We used by-item and by-participant random intercepts, but only a by-participant random slope (the model with maximal random effects structure (Barr et al., 2013) did not converge). When a participant responded that both continuations were equally acceptable, we coded this response as "yes" for the DPro because our research question was whether the use of a DPro is licensed in this particular context. This contributed towards only $1 \%$ of the data.

For the second response, we fitted linear mixed effects models (Baayen et al., 2008) with acceptability rating as the dependent variable. The fixed effects were: 1 . sentence type (three levels: Narrator-judgement, FID and Neutral), 2. pronoun type (two levels: PPro and DPro), and 3. their interaction. Again, we fit two separate models with treatment contrasts: In the first 
model, Neutral was used as reference level and in the second, FID. We included by-participant and by-item random intercepts, together with random slopes only for sentence type (the model with maximal random effects structure did not converge). In the analysis, we dropped all trials for which both options in the forced-choice were selected as equally plausible, which contributed towards $1.1 \%$ of the data.

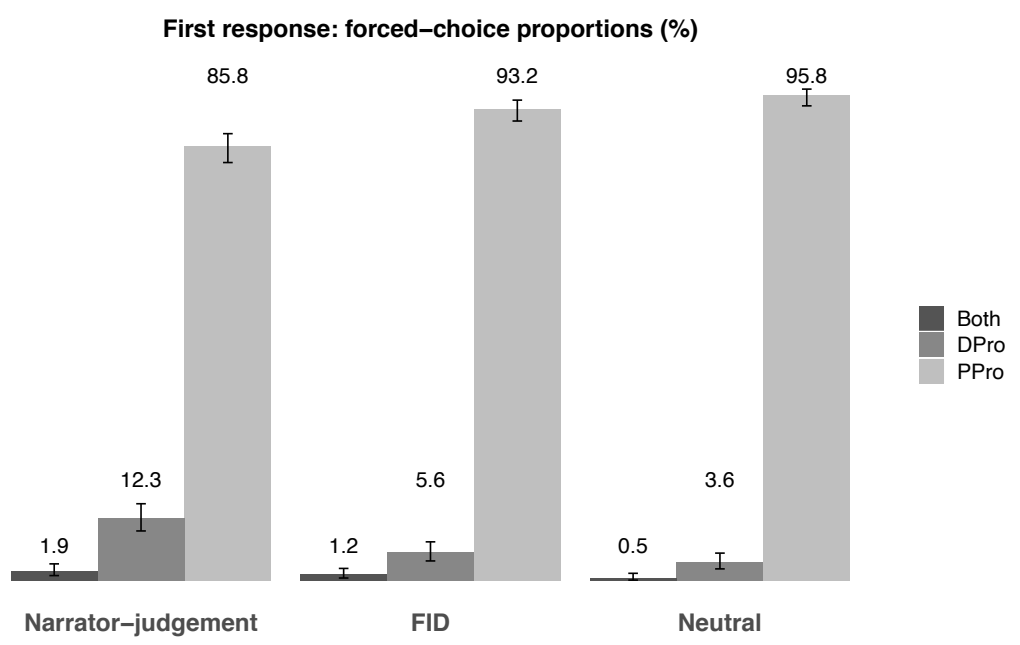

Figure 2. Response proportions for the first task in Experiment 2.

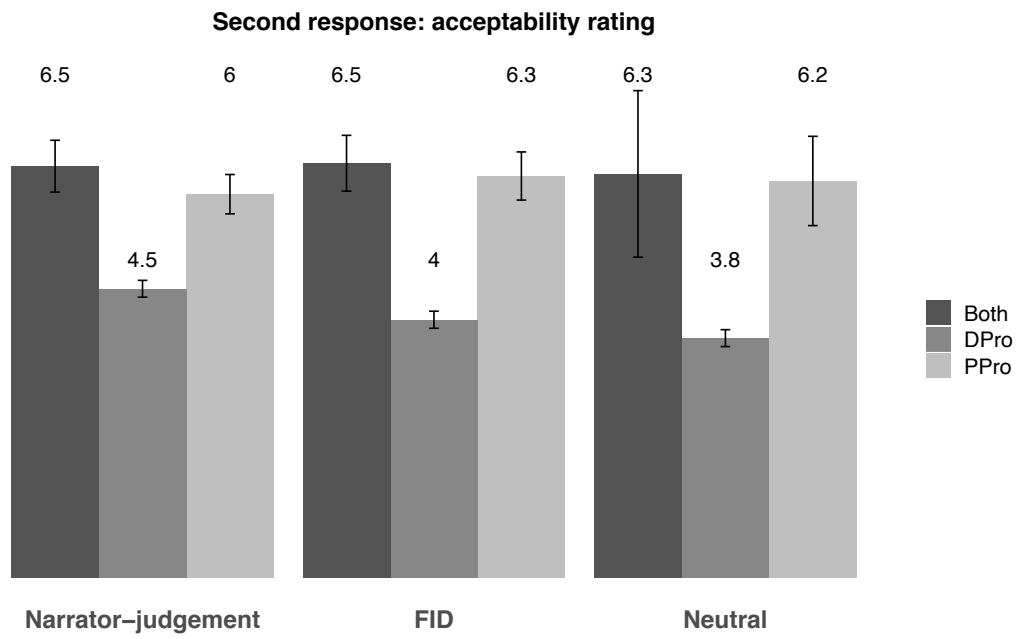

Figure 3. The mean acceptability rating for the continuation that was rated as not native in Experiment 2.

\section{Results}

Response means for the forced-choice task are plotted in Figure 2 and, for the acceptability rating task, in Figure 3. The fixed effects from the linear models for the two types of responses are provided in Tables 2-5. The analysis of the forced-choice task revealed that, compared to the Neutral condition, DPros were chosen significantly more often both in the Narrator-judgement and in the FID conditions.

The analysis of the acceptability judgement task revealed a significant main effect of sentence type. Narrator-judgement and FID sentences were rated as more acceptable than the neutral and Narrator-judgement sentence were rated as more acceptable than FID sentences. Analyses also revealed a significant main effect of pronoun type. The PPro conditions were rated as more acceptable than the DPro conditions. No interaction reached significance, which could be due to the somewhat few instances of acceptability ratings for the DPro conditions: Only about $7 \%$ of all responses in the acceptability rating task were DPro sentences. 


\begin{tabular}{l|rccc} 
Fixed effects & Estimate & Std.Error & $\mathrm{p}$ & \\
\hline Intercept & -5.383 & 0.804 & $2.14 \mathrm{E}-11$ & $*$ \\
FID & 1.304 & 0.774 & 0.092 & . \\
Narrator-judgement & 1.539 & 0.905 & 0.089 & .
\end{tabular}

Table 2: Linear model estimates, standard errors and p-values for the data from the forcedchoice task in Experiment 2. Neutral is the reference level. Estimates for FID and Narratorjudgement show the effect of these two sentence types with respect to sentences in Neutral type.

\begin{tabular}{l|rccc} 
Fixed effects & Estimate & Std.Error & $\mathrm{p}$ & \\
\hline Intercept & -4.507 & 0.537 & $2 \mathrm{E}-16$ & $*$ \\
Neutral & -0.849 & 0.351 & 0.016 & $*$ \\
Narrator-judgement & 1.312 & 0.267 & $9.04 \mathrm{E}-7$ & $*$
\end{tabular}

Table 3: Linear model estimates, standard errors and p-values for the data from the forcedchoice task in Experiment 2. FID is the reference level. Estimates for Neutral and Narratorjudgement show the effect of these two sentence types with respect to sentences in FID type.

\begin{tabular}{l|rrrr} 
Fixed effects & Estimate & Std.Error & t-value & \\
\hline Intercept & 3.789 & 0.181 & 20.946 & $*$ \\
FID & 0.290 & 0.105 & 2.766 & $*$ \\
Narrator-judgement & 0.778 & 0.138 & 5.642 & $*$ \\
Pronoun type & 1.502 & 0.352 & 4.263 & $*$ \\
FID : Pronoun type & 0.103 & 0.382 & 0.269 & \\
Narrator-judgement : Pronoun type & -0.263 & 0.391 & -0.673
\end{tabular}

Table 4: Linear model estimates, standard errors and t-values for the data from the acceptability rating task in Experiment 2. Neutral is the reference level. Estimates for FID and Narratorjudgement show the effect of these two sentence types with respect to sentences in Neutral type; the estimate for Pronoun type shows the effect of PPro with respect to DPro; and estimates for FID : Pronoun type and Narrator-judgement : Pronoun type show the interaction between FID sentences and the type of the pronoun, and Narrator-judgement sentences and the type of the pronoun.

\begin{tabular}{l|rcrc} 
Fixed effects & Estimate & Std.Error & t-value & \\
\hline Intercept & 4.079 & 0.168 & 24.249 & $*$ \\
Neutral & -0.290 & 0.105 & -2.766 & $*$ \\
Narrator-judgement & 0.487 & 0.101 & 4.834 & $*$ \\
Pronoun type & 1.605 & 0.239 & 6.722 & $*$ \\
Neutral : Pronoun type & -0.103 & 0.382 & -0.269 & \\
Narrator-judgement : Pronoun type & -0.366 & 0.282 & -1.297
\end{tabular}

Table 5: Linear model estimates, standard errors and $t$-values for the data from the acceptability rating task in Experiment 2. FID is the reference level. Estimates for Neutral and Narratorjudgement show the effect of these two sentence types with respect to sentences in FID type; the estimate for Pronoun type shows the effect of PPro with respect to DPro; and estimates for Neutral : Pronoun type and Narrator-judgement : Pronoun type show the interaction between Neutral sentences and the type of the pronoun, and Narrator-judgement sentences and the type of the pronoun. 


\section{Discussion}

Experiment 2 largely replicates the results from Experiment 1. The results show that DPros in Narrator-judgement conditions were judged as more acceptable than DPros in the FID and the Neutral conditions. These data are most compatible with the hypothesis that DPros avoid perspectival centers, where topical referents automatically become perspectival centers in the absence of any indication of a speaker or narrator functioning as perspectival center. They are less compatible with the assumption that DPros generally avoid topics, subjects, and/or agents. The results are also less compatible with a variant of the ani-logophoricity hypothesis on which there is only a weak tendency for topical referents to be interpreted as perspectival centers in the absence of any indication of a speaker or narrator functioning as perspectival center. On such an account, DPros are expected to be more acceptable in Neutral than in FID conditions, which is contrary to what we found.

Although the pattern of results of Experiments 1 and 2 was similar, the numerical trend that we observed in Experiment 1 between judgements for the DPro in FID and Neutral conditions turned out to be significant in Experiment 2. This part of the data was not predicted by either variant of the tested accounts. One possible explanation could be that FID is a form of speech that is usually encountered in longer narrative texts with clearly established protagonists. As already said in Section 3.1 above, it is therefore possible that our FIDsentences were perceived not as FID, but rather as the narrator's evaluations by some participants. That is, in the example stimulus in (10e-f), for example, some participants might perhaps have understood the final sentence as claiming that the narrator finds it great that the topic of the discourse (Fabian) will, according to her/his expectations, spend the money for a posh dinner on the evening of the day on which the narrator tells her/his story. Consequently, they accommodated an 'involved' narrator functioning as the perspectival center and the DPro was then not precluded from picking up the discourse topic. An account along these lines raises the question, however, of why it should not also be possible to take the narrator instead of the topical referent as the perspectival center in the Neutral condition, which would likewise be compatible with the anti-logophoricity of DPros. We tentatively suggest that this option is strongly dispreferred for the following reason: In neutral narration there is by definition no indication at all of the presence of a narrator functioning as perspectival center, while the topical discourse referent is highly prominent. It is therefore much more natural to assume the topical referent to be the perspectival center in such cases. Sentences in the FID condition, in contrast, contain perspective-dependent expressions and therefore presuppose a perspectival center, which, for the reasons just mentioned, could not only be the topical referent, but also the narrator.

Given the additional complication just mentioned, studying the interaction of pronoun resolution and determination of the perspectival center would be a fruitful topic for future research. For an item like (10e-f), for example, this could be done by giving participants the additional task of answering a question like Who finds it great that Fabian will spend the money for a posh dinner?, with Fabian, the speaker/narrator, both and I don't know being the available answer options. ${ }^{5}$

One additional and also somewhat unexpected effect that we found in the two experiments was that the DPro in the Narrator-judgement condition was judged to be less acceptable than the corresponding PPro condition. If evaluation from an abstract narrator made the narrator maximally prominent and the discourse topic (relatively) less prominent, the DPro should have been rated as acceptable as the corresponding PPro. We surmise that this contrast emerged because participants followed a prescriptive rule that they were taught at school: DPros are substandard and should therefore be avoided in written texts. Similar effects have also been observed elsewhere. Patil, Bosch and Hinterwimmer (2020) have reported that DPros are very rarely used in written language even in a context that licenses their use as per the prominence constraint. In fact, Hinterwimmer and Patil (2020) report two experiments carried out with the same set of stimuli but in two modalities - written and oral - which show that acceptability of DPros increases considerably with oral presentation (from 3.7 to 5.9 on the 1-7 Likert scale).

\footnotetext{
${ }^{5} \mathrm{We}$ are grateful to an anonymous reviewer for pointing this out to us.
} 


\section{General Discussion and Conclusion}

In this paper, we presented the results of two experimental studies in which we tested the claim in Hinterwimmer and Bosch (2017) that DPros can in fact pick up discourse referents functioning as topics, agents, and subjects, provided that there is a prominent perspectival center available that is distinct from the respective discourse referent. Additionally, we set out to test whether there is only a weak tendency to interpret discourse topics as perspectival centers in the absence of any indication of a speaker or narrator functioning as perspectival center, or whether discourse topics are automatically interpreted as perspectival centers in such cases.

In Experiments 1 and 2, we tested via acceptability studies the claim that DPros could be interpreted as co-referential with topics if the respective sentences clearly express the perspective of a highly involved narrator, thus turning the narrator into a prominent perspectival center. We also tested whether topical referents are more strongly dispreferred by DPros in cases of FID than in neutral continuations, i.e. in continuations where there is no indication of a speaker or narrator functioning as perspectival center.

Our results were more compatible with the stronger version of Hinterwimmer and Bosch's (2017) analysis on which discourse topics are automatically interpreted as perspectival centers in neutral narration than with the weaker version on which there is only a weak tendency for them to be interpreted as perspectival centers in neutral narration: DPros picking up topical referents were rated as most native-like/acceptable in sentences that expressed the narrator's perspective and least native-like/acceptable in neutral continuations, with sentences in FID falling in between. Still, on the stronger version, it is predicted that there are no reliable differences between neutral continuations and FID continuations, not, that sentences in FID are rated better than neutral continuations. We provided some speculative remarks as to why these unexpected results might have come about. However, more research is required to come to more definitive conclusions. In particular, it would be worthwhile to carry out a further experiment in which the stimuli used in Experiments 1 and 2 are presented auditorily, in order to see whether the acceptability of sentences with DPros generally increases, as reported in Section 3.2. above for two other experiments with DPros. Additionally, it would be worthwhile to focus on the interaction of pronoun resolution and determination of perspectival centers in further experimental studies.

We would like to end this paper by pointing out that an alternative to the anti-logophoricity hypothesis is briefly mentioned in Hinterwimmer and Bosch (2017) that also seems to be compatible with the experimental results reported in this paper. On the alternative, a strictly prominence-based account, DPros generally avoid the most prominent discourse referents as antecedents or binders. In the absence of perspectival centers (i.e. in instances of neutral narration), topics (or, in cases of binding, subjects) are maximally prominent. If there is a perspectival center, in contrast, the perspectival center is maximally prominent. One option to make this alternative account work would be to assume, first, that while speakers automatically introduce discourse referents (Hunter, 2013), narrators only introduce discourse referents when there is an indication of them being present as perspectival centers (see Altshuler and Maier, to appear for relevant discussion). Second, one would have to assume that discourse referents introduced by narrators are more prominent than topical discourse referents, which does not seem obvious. In light of this additional complication, and since its empirical predictions do not differ from those of the strong version of the anti-logophoricity account, ${ }^{6}$ we chose not to pursue the prominence-based account in this paper. Teasing apart the predictions of the strong version of the anti-logophoricity account and the prominence-based account is a topic that we are planning to come back to in future research, however.

\footnotetext{
${ }^{6} \mathrm{We}$ are grateful to two anonymous reviewers for pointing this out to us.
} 


\section{Acknowledgements}

We would like to thank Sara Meuser, Janne Schmandt, Felix Jüstel, Magdalena Schmitz and Carina Rothkegel for help in preparing and running the experiments reported in this paper, and the audience at the 7th biannual Experimental Pragmatics Conference in Cologne and at the XPrag meeting at the University of Graz 2018 for comments and discussion. The research reported in this paper was funded by a research grant from the Deutsche Forschungsgemeinschaft (DFG) for the project Bound-variable-like interpretations of demonstrative pronouns, complex demonstratives and definite descriptions and for the project C05 Discourse referents as perspectival centers of the Collaborative Research Center 1252 Prominence in Language (University of Cologne).

All experimental stimuli, data and statistical analyses related to the research reported in this paper are accessible via the following link: https://osf.io/7ce94/

\section{References}

Altshuler, David and Emar Maier. Death on the freeway: Imaginative resistance as narrator accommodation. In Ilaria Frana, Paula Menendez Benito and Rajesh Bhatt (eds), Making worlds accessible: Festschrift for Angelika Kratzer. Amherst: UMass Scholar Works, forthcoming.

Baayen, R. Harald., Douglas J. Davidson and Douglas M. Bates (2008). Mixed-effects modeling with crossed random effects for subjects and items. Journal of Memory and Language 59, 390-412.

Banfield, Ann (1982). Unspeakable sentences: Narration and representation in the language of fiction. Boston: Routledge.

Barr, Dale J., Roger Levy, Christoph Scheepers and Harry J. Tily (2013). Random effects structure for confirmatory hypothesis testing: Keep it maximal. Journal of Memory and Language, 68(3), 255-278.

Bosch, Peter, Graham Katz and Carla Umbach (2007). The non-subject bias of German demonstrative pronouns. In Monika Schwarz-Friesel, Manfred Consten and Mareille Knees (eds.), Anaphors in text, 145-164. Amsterdam and Philadelphia: Benjamins. DOI: https://doi.org/10.1075/slcs.86.13bos

Bosch, Peter and Carla Umbach (2006). Reference determination for demonstrative pronouns. In Dagmar Bittner and Natalia Gagarina (eds.), Proceedings of the conference on intersentential pronominal reference in child and adult language (ZASPiL 48), 39-51. Berlin: Zentrum für Allgemeine Sprachwissenschaft, Sprachtypologie und Universalforschung.

Brinton, Laurel (1980). 'Represented perception': A study in narrative style. Poetics, 9: 363 381.

Charnavel, Isabelle (2019). Locality and logophoricity: A theory of exempt anaphora. In Oxford Studies in Comparative Syntax. Oxford University Press.

Charnavel, Isabelle and Victoria Mateu (2015). The clitic binding restriction revisited: Evidence for antilogophoricity. The Linguistic Review 32(4), 671-701.

Clements, George N. (1975). The logophoric pronoun in Ewe: Its role in discourse. The Journal of West African Languages 10: 141-177.

Doron, Edit (1991). Point of view as a factor of content. In Steven K. Moore and Adam Z. Wyner (eds.), Proceedings of Semantics and Linguistic Theory (SALT) I. Cornell University, Ithaca, NY, 51-64.

Dowty, David (1991). Thematic proto-roles and argument selection. Language 67. 547-619.

Dubinsky, Stanley J. and Robert Hamilton (1998). Epithets as antilogophoric pronouns. Linguistic Inquiry 29. 685-693.

Eckardt, Regine (2014). The semantics of free indirect discourse. How texts allow to mindread and eavesdrop. Leiden: Brill. 
Farner, Geir (2014). Literary fiction: The ways we read narrative literature. New York, NY: Bloomsbury Academic.

Geographical distribution of German speakers. (n.d.). In Wikipedia. Retrieved January 12 , 2020, from https://en.wikipedia.org/wiki/Geographical_distribution_of_German_speakers.

Gibson, Edward and Evelina Fedorenko (2013). The need for quantitative methods in syntax and semantics research. Language and Cognitive Processes, 28(1-2): 88-124.

Hinterwimmer, Stefan (2015). A unified account of the properties of German demonstrative pronouns. In Patrick Grosz, Pritty Patel-Grosz and Igor Yanovich (eds.), The proceedings of the workshop on pronominal semantics at NELS 40, 61-107. Amherst, MA: GLSA Publications, University of Massachusetts.

Hinterwimmer, Stefan and Peter Bosch (2017). Demonstrative pronouns and propositional attitudes. In Pritty Patel-Grosz, Patrick G. Grosz and Sarah Zobel (eds.), Pronouns in embedded contexts (Studies in Linguistics and Philosophy), 105-144. Dordrecht: Springer.

Hinterwimmer, Stefan and Andreas Brocher (2018). An experimental investigation of the binding options of demonstrative pronouns in German. Glossa: A Journal of General Linguistics, 3(1), 77. DOI: http://doi.org/10.5334/gjgl.150

Hunter, Julie (2013). Presuppositional indexicals. Journal of Semantics 30 (3), 381-421. DOI: https://doi.org/10.1093/jos/ffs013

Jaeger, T. Florian (2008). Categorical data analysis: Away from ANOVAs (transformation or not) and towards Logit Mixed Models. Journal of Memory and Language 59, 434-446.

Kaiser, Elsi (2010). Effects of contrast on referential form: Investigating the distinction between strong and weak pronouns. Discourse Processes 47. 480-509. DOI: https://doi. org/10.1080/01638530903347643

Kaiser, Elsi (2011a). On the relation between coherence relations and anaphoric demonstratives in German. In Ingo Reich, Eva Horch and Dennis Pauly (eds.), Proceedings of Sinn und Bedeutung 15, 337-351. Saarbrücken: Saarland University Press.

Kaiser, Elsi (2011b). Salience and contrast effects in reference resolution: The interpretation of Dutch pronouns and demonstratives. Language and Cognitive Processes 26(10). 15871624. DOI: https://doi.org/10.1080/01690965.2010.522915

Kaiser, Elsi (2013). Looking beyond personal pronouns and beyond English: Typological and computational complexity in reference resolution. Theoretical Linguistics 39. 109-122. DOI: https://doi.org/10.1515/tl-2013-0007

Kaiser, Elsi and John C. Trueswell (2008). Interpreting pronouns and demonstratives in Finnish: Evidence for a form-specific approach to reference resolution. Language and Cognitive Processes 23(5). 709-748. DOI: https://doi.org/10.1080/01690960701771220

van Krieken, Kobie (2018). Ambiguous perspective in narrative discourse: Effects of viewpoint markers and verb tense on readers' interpretation of represented perceptions. Discourse Processes, 55:8, 771-786,

Maier, Emar (2015). Quotation and unquotation in free indirect discourse. Mind \& Language $30,345-373$.

Mayol, Laia and Robin Clark (2010). Pronouns in Catalan: Games of partial information and the use of linguistic resources. Journal of Pragmatics 42. 781-799. DOI: https://doi. org/10.1016/j.pragma.2009.07.004

Nishigauchi, Taisuke (2014). Reflexive binding: Awareness and empathy from a syntactic point of view. Journal of Est Asian Linguistics 23.157-206.

Palmer, Alan (2004). Fictional minds. Lincoln, NE: University of Nebraska Press.

Patel-Grosz, Pritty (2014). Epithets as de re pronouns. In Christopher Piñón (ed.), Empirical issues in syntax and semantics 10.

Patel-Grosz, Pritty and Patrick G. Grosz (2017). Revisiting pronominal typology. Linguistic Inquiry 48. 259-297. DOI: https://doi.org/10.1162/LING a 00243

Patil, Umesh, Peter Bosch and Stefan Hinterwimmer (2020). Constraints on German diese demonstratives: language formality and subject-avoidance. Glossa. A Journal of General Linguistic, 5(1), 14. DOI: http://doi.org/10.5334/gigl.962

Pearson, Hazel (2015). The interpretation of the logophoric pronoun in Ewe. Natural Language Semantics 23. 77-118. 
Primus, Beatrice (1999). Cases and thematic roles - ergative, accusative and active. Tübingen: Niemeyer.

Primus, Beatrice (2006). Hierarchy mismatches and the dimensions of role semantics. In Ina Bornkessel, Matthias Schlesewsky and Bernard Comrie (eds.), Semantic role universals and argument linking. Theoretical, typological and psycholinguistic perspectives. Berlin: de Gruyter, 53-88.

$\mathrm{R}$ Core Team (2018). R: A language and environment for statistical computing [Computer software manual]. Vienna, Austria. Retrieved from https://www.R-project.org

Schlenker, Philippe (2004). Context of thought and context of utterance. A note on free indirect discourse and the historical present. Mind and Language 19, 279-304.

Schütze, Carson T. and Jon Sprouse (2014). Judgment data. In R. Podesva and D. Sharma (eds.), Research methods in linguistics. Cambridge: Cambridge University Press.

Schütze, Carson T. (2016). The empirical base of linguistics: Grammaticality judgments and linguistic methodology. Language Science Press.

Schumacher, Petra B., Manuel Dangl \& Elyesa Uzun (2016). Thematic role as prominence cue during pronoun resolution in German. In Anke Holler and Katja Suckow (eds.), Empirical perspectives on anaphora resolution, 213-240. Berlin: de Gruyter. DOI: https:// doi.org/10.1515/9783110464108-011

Schumacher, Petra B., Leah Roberts and Juhani Järvikivi (2017). Agentivity drives real-time pronoun resolution: Evidence from German er and der. Lingua 185. 25-41. DOI: https:// doi.org/10.1016/j.lingua.2016.07.004

Sells, Peter (1987). Aspects of logophoricity. Linguistic Inquiry 18. 445-479.

Sharvit, Yael (2008). The puzzle of free indirect discourse. Linguistics and Philosophy 31, 353-395.

Sundaresan, Sandhya (2012). Context and (co)reference in the syntax and its interfaces. $\mathrm{PhD}$ thesis, University of Stuttgart.

Wiltschko, Martina (1998). On the syntax and semantics of (relative) pronouns and determiners. Journal of Comparative Germanic Linguistics 2. 143-181.

Yashima, Jun (2015). Antilogophoricity: In Conspiracy with the Binding Theory. Ph.D. thesis, University of California, Los Angeles. 